\section{Evolutionary genetics}

\section{Ambiguous role of CCR5 in Y. pestis infection}

Arising from: J . Mecsas et al. Nature 427, 606 (2004)

V ecsas and colleagues suggest that a deficiency in the chemokine receptor CCR5 in humans is unlikely to confer protection against plague, based on their study of Yersinia pestis infection in Ccr5- deficient mice. ${ }^{1}$ They were testing the hypothesis that a mutation in the CCR5 gene, frequently found in Caucasians, may have been selected for in the past because it provided protection against (bubonic) plague $^{2-7}$; the mutation, called CCR5 $\Delta 32$, is characterized by a 32-base-pair deletion. We have also tested this hypothesis by using $Y$. pestis infection in mice and, in addition, we have done phagocytosis experiments with macrophages from wild-type and Ccr5-deficient mice. Although, like M ecsas et al., we did not see any difference in the survival of the two groups of mice, we did find that there was a significantly reduced uptake of $Y$. pestis by $C$ cr5-deficient macrophages in vitro. Our results indicate that the role of $\mathrm{Ccr} 5$ in $\mathrm{Y}$. pestis infection may therefore be more complex than previously thought.

In humans, macrophages are targeted by $Y$. pestis, the causative agent of plague, and are therefore important for successful infection. We tested whether $\mathrm{Ccr} 5$ affects the uptake of $Y$. pestisby macrophages in vitro by using peritoneal macrophages from $\mathrm{C} \mathrm{Cr} 5^{+/+}$ and $\mathrm{Crr}^{-1-}$ mice in phagocytosis assays. The uptake by $\mathrm{C} \mathrm{Cr} 5^{-1-}$ macrophages was about 30 -fold lower than that by $\mathrm{C} c 5^{+1+}$ macrophages (Fig. 1a; six independent be specific to Y. pestis. units(CFU) (Fig. 1C). samerateas $\mathrm{Cr} 5^{+/+}$mice. experiments). Our preliminary results indicate that the uptake of Yersinia pseudotuberculosisby macrophages from $\mathrm{C} \mathrm{cr} 5^{-1-}$ miceis much less inhibited in similar experiments (Fig. 1b), suggesting that the inhibition may

To test the effect of $\mathrm{Ccr} 5$ on survival after $Y$. pestis infection, groups of specific pathogen-free $\mathrm{C} \mathrm{Cr} 5^{+/+}$and $\mathrm{C} \mathrm{Cr} 5^{-1-}$ mice were challenged with lethal inocula of $Y$. pestis $G B$, a highly virulent strain isolated from a fatal human case of plague. H owever, there was no significant difference in survival between the groups, even after infection with a low dose of two colony-forming

Our survival data are in agreement with those of Mecsas et al. ${ }^{1}$, although we used a strain of $Y$. pestis with a different degree of virulence ( $G B$ rather than $\mathrm{KIM}$ ), mice with a different genetic background (C57BL/6 rather than $\mathrm{BALB} / \mathrm{C}$ ) and a different route of infection (subcutaneous rather than intravenous). O ur results show that $\mathrm{C} \mathrm{cr} 5^{-1-}$ mice arenot protected against infection with afatal human isolate of $Y$. pestis and succumb at the

Although these results seem to disprove the'plaguehypothesis', somedoubts remain. We consistently observed a marked reduction in the uptake of $Y$. pestis by $\mathrm{C} \mathrm{Cr} 5^{-1-}$ macrophages in vitro that appears to be spe cific to this species of Yersinia. The Y. pestis strain that caused the great plague pandemic in thefourteenth century wasprobably quite a

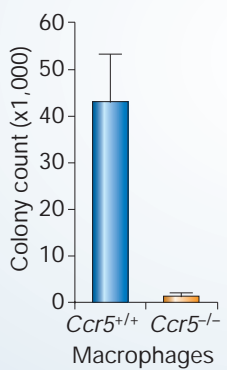

b

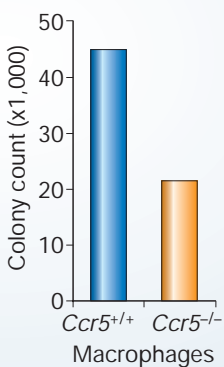

c

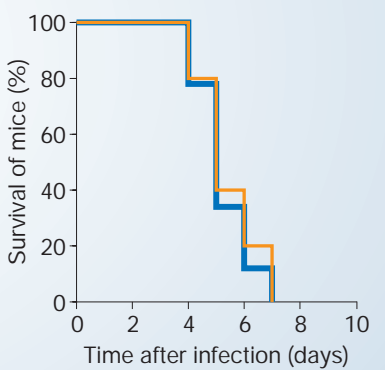

Figure 1 Ccr5 influence on the uptake of bacteria by macrophages in vitro and on the survival of mice infected with Yersinia pestis. $\mathbf{a}, \mathbf{b}$, The intracellular bacteria recovered from peritoneal macrophages isolated from C57BL/6 CCr5 ${ }^{+/+}$and $\mathrm{CCr} 5^{-1-}$ mice and incubated ( $1 \times 10^{6}$ cells for $1 \mathrm{~h}$ at $37^{\circ} \mathrm{C}$ ) with a, Y. pestis GB (multiplicity of infection, 10 colony-forming units (CFU); mean \pm s.e.m.) or $\mathbf{b}$, Y. pseudotuberculosis strain IP32953. Gentamycin was used to kill extracellular bacteria. c, Survival of C57BL/6 C Cr5 $5^{+1+}$ mice (blue; $n=9$ ) and $\mathrm{Ccr} 5^{-1-}$ mice (orange; $n=10$ ) after challenge with 2 CFU Y. pestis GB (Biovar orientalis, $\mathrm{Pgm}^{+}, \mathrm{LCrV}^{+}$; median lethal dose is $1 \mathrm{CFU}$ ) subcutaneously. different from the twentieth-century isolate used for theinfection experiments discussed here. Genomeanalysis indicatesthat Y. pestis evolved rapidly from an enteric organism, which was spread by the faecal-oral route, to a flea-transmitted pathogen of rodents and humans, with acquisition of novel virulence mechanismsalongtheway, ${ }^{8,9}$.

In addition, the pathogenesis of $Y$. pestis infection may not be comparable when delivered by injection of micein thelaboratory rather than by flea-bornetransmission to humans ${ }^{10}$, because infection may be more rapid and acute. The dose of plague bacteria delivered by flea-borne transmission is likely to be more variable and the outcome of infection to depend on an interaction between the pathogen, vector and mammalian host. A previous infection leading to preactivation of the host's immunesystem would changethe courseof a subsequent $Y$, pestis infection - as would be expected in people living in the $\mathrm{M}$ iddle Ages, who were constantly encountering all kinds of infection and in whom a resi stance to plague could have developed in association with theCCR $5 \Delta 32$ mutation.

Under thesecircumstances, firm conclusions cannot be drawn from the negative results obtained in $\mathrm{Ccr} 5$-deficient mice. Taking all these arguments into consideration, the data on the role of CCR5 in Y. pestis infection are still inconclusive because the situation seems to be more complex than previously anticipated.

Stephen J. Elvin*, E. Diane Williamson*, Joanne C. Scott*, Jeremy N. Smith*, Guillermo Pérez de Lemat, Silvia Chilla†, Paul Clapham‡, Klaus Pfeffer§, Detlef Schlöndorfft, Bruno Luckow† *D efence Science and Technology Laboratories, Porton D own, Salisbury SP4 0J Q, UK e-mail: dewilliamson@dstl.gov.uk

†Klinikum der Universität M ünchen, M edizinische Poliklinik-Innenstadt, 80336 M ünchen, Germany fUniversity of M assachusetts, Worcester,

M assachusetts 01605, USA

$\S$ H einrich-H eine Universität Düsseldorf, 40225

Düsseldorf, Germany

doi:10.1038/nature02822

1. Mecsas, J. et al. Nature 427, 606 (2004).

2. Blanpain, C., Libert, F., Vassart, G. \& Parmentier, M. Recept. Chann. 8, 19-31 (2002).

3. Samson, M. et al. N ature 382, 722-725 (1996)

4. Liu, R. et al. Cell 86, 367-377 (1996).

5. Dean, M. et al. Science 273, 1856-1862 (1996).

6. Stephens, J. C. et al. Am. J. Hum. Genet. 62, 1507-1515 (1998)

7. Libert, F. et al. Hum. M ol. Genet. 7, 399-406 (1998).

8. Parkhill, J. et al. Nature $413,523-527$ (2001).

9. Wren, B. W. Nature Rev. M icrobiol. 1, 55-64 (2003)

10. Jarrett, C. O., Sebbane, F., Adamovicz, J. J., Andrews, G. P. \& Hinnebusch, B. J. Infect. Immun. 72, 2052-2056 (2004). 